\title{
Herbert's Pits and Lid Concretions: an Important Association
}

\author{
L. C. CHUMBLEY
}

Jerusalem

\begin{abstract}
Summary
A prospective study of 2,000 eyes of 1,000 consecutive unselected ophthalmic outpatients showed that Herbert's pits and superior tarsal conjunctival concretions are significantly associated conditions. Fifty per cent of eyes with Herbert's pits were found to have superior tarsal conjunctival concretions, compared with four per cent of eyes without Herbert's pits. Furthermore, a strong correlation between the degree of Herbert's pits and the degree of development of concretions was demonstrated.
\end{abstract}

Herbert's pits are a characteristic and pathognomonic physical finding of trachoma. While conducting systematic surveys of trachoma, the author was struck by a possible association between Herbert's pits and concretions of the superior tarsal conjunctiva, but could find no reference in the literature to this association. This report presents the results of a prospective study of the relationship between these two conditions.

\section{Method}

A series of 1,000 consecutive unselected ophthalmic outpatients was studied at St. John Ophthalmic Hospital in Jerusalem. Detailed, complete eye examinations were performed, and included Haag Streit slit lamp biomicroscopic examination of the external eye and of the everted upper and lower eyelids of both eyes for all patients. Herbert's pits were graded from $0-4$ as follows:

0 = absent

$1+=1-3$ typical pits

$2+=>3$ pits, but not entire upper limbus

$3+=$ entire upper limbus involved

$4+=$ cornea encircled
Concretions of the superior tarsal conjunctiva were graded from 0 - 3 as follows:

$$
\begin{aligned}
& 0 \quad=\text { absent } \\
& 1+=\text { few }, \text { covered } \\
& 2+=\text { few, uncovered } \\
& 3+=\text { many, covered or uncovered }
\end{aligned}
$$

\section{Results}

There were 2,000 eyes in the study. The results are summarised in Table I. There was a marked positive correlation between the presence of Herbert's pits and the presence of concretions of the superior palpebral conjunctiva as shown in Figure 1. Gamma values (gamma measures strength of association, 0 $=$ none,$+1=$ invariably present) for right and left eyes computed separately were high $(+0.85$ right, $=0.86$ left $)$ indicating in addition, a strongly positive correlation between the degree of Herbert's pits formation and the degree of superior palpebral conjunctival concretions.

\section{Discussion}

Herbert in 1904 described the typical pitting, characteristic of trachoma, that is associated with his name. One cannot do better than 
Table I. Superior tarsal palpebral concretions

\begin{tabular}{llrrrr} 
& & \multicolumn{1}{c}{0} & $1+$ & $2+$ & $3+$ \\
\cline { 3 - 6 } & 0 & 1621 & 37 & 18 & 9 \\
Herbert's & $1+$ & 24 & 10 & 4 & 6 \\
Pits & $2+$ & 53 & 17 & 13 & 10 \\
& $3+$ & 68 & 27 & 36 & 24 \\
& $4+$ & 11 & 2 & 9 & 0 \\
\hline
\end{tabular}

Distribution of 2,000 eyes of 1,000 consecutive unselected ophthalmic outpatients, classified according to Herbert's pits and superior tarsal palpebral concretions. See text for details of classification.

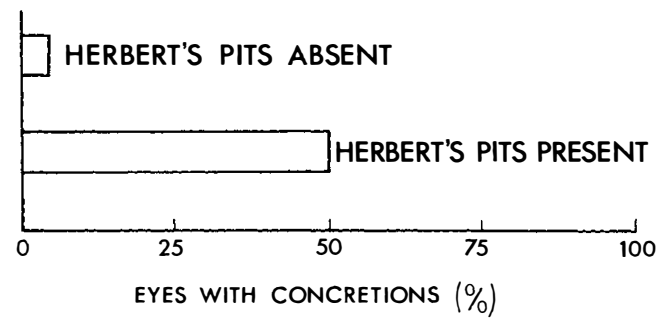

Fig. 1. Graph showing the relationship between the percentage of eyes with superior tarsal concretions in eyes with Herbert's pits. The difference between groups is statistically significant. $(P>0.001)$

quote his original description. "The lower illdefined border (of chronic trachomatous pannus) is interrupted by a number of small sharply defined semicircular indentations or bays. In cases where the abnormal opacity has extended a little further downwards, in place of these bays or notches we find fully enclosed round islands, less opaque than their surroundings. On careful examination they are found to be slightly depressed below the neighbouring surface, and in natives of India more or less pigmented. Their number averages about half a dozen, but they are often rather fewer, or rarely there may be as many as a dozen". ${ }^{1}$
Herbert's pits are currently believed to be the sequelae of sloughed limbal follicles, where transparent corneal epithelial cells make good the ulcerated defects, filling the cavities until flush with the rest of the ocular surface. Concretions of the palpebral conjunctiva are not specific for trachoma, and may follow conjunctival damage from other disease processes. Pathologically they appear as masses of essentially hyaline composition retained in small depressions and tubular recesses in the conjunctiva, with a surrounding area of lymphocytic infiltration. On the other hand, concretions may be seen as a consequence of post trachomatous degeneration. As has been shown in this study, they are strongly associated with Herbert's pits. Removal of those concretions causing symptoms is a great help to the patient. This information is valuable as many ophthalmologists are working in countries where a high prevalence of trachoma exists.

If Herbert's pits are noted, it is important to evert the upper eyelid even though this may prove difficult. This difficulty is due to the presence of trichiasis or the absence of lashes which have been epilated. These patients often employ eye ointments, making the manoeuvre technically more difficult. Lastly, due to shrinkage of the fornix and tightness and distortion of the lid by the trachomatous process, eversion around the axis of the upper tarsal border is a difficult procedure. Mindful of the association described in this report ophthalmologists should search for concretions in patients presenting with Herbert's pits.

\section{References}

${ }^{1}$ Herbert $\mathrm{H}$ : Trachomatous pannus and associated changes. Trans Ophthalmol Soc UK 1904; 25: $67-77$. 